\title{
Amansar inimigos: práticas de predação feminina e a consanguinização da alteridade
}

\author{
PATRICLA CARVALHO ROSA
}

INSTITUTO DE DESENVOLVIMENTO SUSTENTÁVEL MAMIRAUÁ (IDSM), TEFÉ/AM, BRASIL

HTTPS://ORCID.ORG/OOOO-000I-7570-3702

Casar com esse homem de fora foi um jeito de mulher caçar, mas marido. Fui amansando o jeito dele ser, fazendo ele ficar como a gente gosta, num parente, num homem ticunado. [...] Na nossa cultura gente de fora pode virar parente, só que antes, tem que deixar de ser awane [inimigo].

A proposição acima foi desenvolvida em meados de julho de 2014 por Constância, hoje com pouco mais de 55 anos e uma das interlocutoras Ticuna que acompanhou o trajeto da pesquisa da qual provêm as narrativas e reflexões aqui expostas (Rosa, 2015). A proposição foi registrada em diários de campo da época e ilustra um pouco do que aprendi com ela, com outros de seus parentes ticuna e conterrâneos de aldeia sobre o que diziam e experimentavam a respeito do lugar das práticas matrimonias e dos sentidos construídos às conjugalidades na produção do parentesco.

Para isso, durante minhas estadias com eles, habitantes em territórios no alto curso do rio Solimões, no Amazonas, entre 2013 e 2017, adotei a estratégia da parcialidade sugerida por Donna Haraway (1991[1988]) e aprendi a escutar e conectar narrativas dotadas de conhecimentos situados e localizados dentro de experiências heterogêneas, permeáveis de poder e particularidades concernentes às práticas de casamento. Com esse interesse acertado reciprocamente, mas não isolado de tensões, a pesquisa se propunha a conhecer e discutir com os interlocutores, homens e mulheres, em diferentes fases da vida, posições sociais e identidades de gênero, como criavam e gerenciavam as políticas de convivências das quais me falavam e seus lugares nas arenas de negociações de alianças e critérios maritais.

Para que isso ocorresse, a etnografia, antes de ser um método de coleta de dados, funcionou nessa situação como um princípio de relação colaborativa para conectar e dar sentidos contextualizados e afetados às problemáticas dos agentes envolvidos (Rappaport, 2007; de la Cadena, 2015). Nessa 
postura de escuta, em nossos diálogos cotidianos - nem sempre compreensíveis e possíveis de traduções recíprocas -, tentei ouvi-los e aprender como aquilo que conhecemos por casamento (nïigü) conjuga entre eles um conjunto de ações variadas, associadas a duas ideias centrais na política relacional do grupo: uma articulada aos idiomas ticuna da produção da pessoa, do corpo e, outra, por consequência, do parentesco. Juntas, tais ideias engendram os mecanismos indígenas para controle de semelhança e diferença.

Nessa engrenagem, a primeira das ideias que mobilizaram nossos diálogos mostra o casamento como relação de engajamentos num compromisso ou parcerias de casal, formalizados, no âmbito dos vínculos conjugais, pela corresidência e pelo fabricar parentes (filhos/as). E, complementar a arena das interações do casal, fala-se de uma segunda ideia relacional ticuna, associada, desta vez, às configurações sociais de obrigações ou atividades/trabalhos (porãâäu), atrelada aos domínios das alianças e de reciprocidade estendidas para além do espaço doméstico e da intimidade. Assim, inspirado nessas proposições, ni’gü̈ aparece nas falas dos interlocutores correspondendo às extensões das micropolíticas de aliança efetivadas quando o casal assume o vínculo afetivo-sexual, atuando nas posições de marido (nate) e esposa (namâ). A partir dessas posições, o par conjugal é inserido na condição de cunhado(as) ou tios(as), constituindo-se enquanto parte compósita num circuito de reciprocidades com os afins adquiridos e de continuidade com seus consanguíneos.

Constância disse-me, em certa ocasião, que ni’igü era um jeito dos ticuna estarem se fazendo como parente; estar se fazendo parente junto com alguém e com os parentes. Essas duas últimas proposições produziram uma convenção etnográfica situada no tempo e nos espaços desses diálogos (Rosa, 2015), apontando que casar e constituir conjugalidade comunicam para essas redes de interlocuções indígenas formas de criar e caracterizar as relações entre pessoas, suas capacidades agentivas e fazer aparecer domínios generizados de socialidades. As conjugalidades e alianças matrimoniais conformam, ao mesmo tempo, regimes complexos de saberes, estruturas de troca e etiquetas políticas que acionam um pano de fundo próprio das teorias de relação dos interlocutores, não homogêneas e instáveis, que nos falam sobre como a identidade e a alteridade estabelecem os gradientes de diferenciação entre eles e seus outros e produzem e se moldam nas relações conjugais.

Revisitando essas operações indígenas, observa-se que as lógicas semânticas e políticas ticuna relacionadas aos critérios de aliança indicam conteúdos que gerem as distinções entre modos de casar-se certo (meã cü nïi) e se casar errado (tchire cü nỉ). Sobre esse quadro classificatório, argumentei alhures (Rosa, 2013, 2015, 2019) que, na perspectiva intraétnica, casar-se bem implica seguir a regra exogâmica, com proeminência de escolha do par conjugal na posição terminológica tchautáa, que engloba, sem distinção de gênero, os primos cruzados bilaterais como possibilidade valorizada de vínculo conjugal, preferencialmente produzida com alguém na mesma geração e proximidades territoriais (Goulard, 1998; Goulard \& Barry, 1998; Rosa, 2015). Assim posto, a regra das nações, como nominam os interlocutores essas estruturas de troca, emerge como um dispositivo de controle sociopolítico do parentesco 
e das socialidades ticuna ${ }^{1}$, operando como um princípio relacional fazendo operar um instrumento de relação controlada com a diferença (Viveiros de Castro, 1996, 2002a).

Numa escala intraétnica, tal premissa está fortemente correlacionada, como dito, ao princípio coextensivo de produção da pessoa do parentesco, tornando o conceito de womãtchi (incesto clânico e consanguíneo) num dispositivo de evitação do excesso de semelhança, cuja condição é o reverso assimétrico do parentesco; é uma contrarrelação; imprime sentido de perigo na relação, associado à ideia de ameaça ao que afirmam serem atributos da condição moral e política do bom esposo ou boa esposa. Como um vetor antissocial de produção criativa ao parentesco, da pessoa e da aliança, casar-se errado poderia ser sintetizado, no âmbito das teorias indígenas ouvidas, pelo descumprimento do método de classe, no sentido antropológico empregado por Lévi-Strauss $(2011$ [1947])². A partir desse modelo, práticas de constituir alianças matrimoniais assumem diversos critérios e formatos, a depender dos marcadores sociais de diferença por eles administrados e das conjunturas políticas, religiosas, territoriais, econômicas, em que vivem os interlocutores ${ }^{3}$.

Nesse texto, nosso fio condutor serão os relatos e diálogos sobre o matrimônio de Constância e as novas luzes que lança ao repertório etnográfico e bibliográfico sobre perspectivas Ticuna de suas relações de parentesco e aliança. As experiências e reflexões de Constância possibilitaram conhecer, inicialmente, o campo das socialidades matrimoniais interétnicas, e, conforme conversávamos, as suas narrativas remeteram-me para situações em campo em que ela me contava das capacidades predatórias femininas relacionadas com ações de amansar, aqui dimensionadas com a ideia de domesticação de uma categoria particular de afinidade exterior masculina. Trazendo em cena o caso do seu marido de fora levam-se a sério (Viveiros de Castro, 2004; Archambault, 2016) as proposições de Constância, em dois pontos principais: ao enunciar que em sua cultura gente de fora pode virar parente, e, que, para isso ocorrer, antes, tem que deixar de ser awane [inimigo]".

Para tanto, amansar marido torna-se a categoria de análise. Para compreendê-la, se faz necessário perpassarmos alguns elementos heurísticos que nos conduzirão aos sentidos indígenas de outro termo relacional relevante na discussão: gente de fora. Discutidos esses pontos sobre os gradientes e as categorias relacionais, passamos ao processo de amansar marido narrado por Constância, argumentando que o casamento seria um conjunto particular de ações de predação familiarizante feminina. $\mathrm{O}$ amansar marido realizado aqui se expressa algo símile à equação entre a produção e controle da afinidade matrimonial com a afinidade potencial. Isso se passa, no caso analisado, através da gramática da comensalidade e do cuidado, e deixam-se ver nessas dinâmicas as agências femininas na modulação dos processos de predação do inimigo.

$1 \mathrm{Na}$ discussão etnológica, concorda-se que entre os Ticuna opera um princípio relacional no qual o matrimônio está orientado pela lógica da exogamia, proposta pelo par de metades ngechïigü (sem penas) e achïigü (com penas). Estas unidades classificatórias herdadas dos demiurgos os organizaram em clãs (cuã), de modo que passassem a evitar a ocorrência de novos episódios de incestos (womãtchi), colocando em marcha, desde então, as metades/clãs/nações enquanto marcador central de identidade Ticuna.

2 Assumindo a perspectiva de parente womãtchi, a pessoa Ticuna e suas agentividades ficam impedidas de readquirir a condição de imortalidade post mortem. Na filosofia política do grupo, estes parentes têm os seus corpos-pensamentos (mẩü) devorados pela demiurga Ta'e, cujos fios de cabelos-pensamentos sustentam a náane, conceito indígena associado à relação coextensiva do território e à fabricação de pessoas e parentes. Cf: Nimuendaju (1972[1952]), Oliveira Filho (1988), Goulard (1998) e Santos Angarita (2010).

3 Sobre como operam outros exemplos de atualizações das regras das nações, impulsionadas por essas variáveis, ler Rosa (2015). 
Nesse horizonte, retomamos o argumento de Cecilia McCallum (2002), Tânia S. Lima (2005), entre outras etnólogas (C. Hugh-Jones, 1979; Overing, 1986; Belaunde, 2001; McCallum, 2001; Lea, 1999; Lasmar, 1999, 2005, 2008; Santos, 2019), relacionado à agência feminina evidenciada avessa a qualquer determinação periférica, associada com a noção de economia da domesticidade ou consanguinidade (Descola, 2001; Fausto, 2001; Viveiros de Castro, 2002a, 2002b). Nessas perspectivas, concorda-se que as atividades femininas também estão atuantes criativamente na relação entre consumo da alteridade e produção da identidade. Com efeito, se, de acordo com o corolário etnológico, "a predação é um momento do processo de produção de pessoas do qual a familiarização é o outro" (Fausto, 2001: 418), propõe-se aqui a vê-la desde o crivo da perspectiva das ações cotidianas e femininas.

\section{Gentes de fora: conexóes no tempo e nos espaços}

Os Ticuna, ou Magüta como se denominam, são falantes de língua epônima e habitam as margens e interflúvios do rio Solimões. A maior parte de seus territórios encontra-se no alto curso do rio, justapostos na tríplice fronteira que intersecciona Brasil, Peru e Colômbia, e cuja configuração resulta dos continuados processos de territorialização, desencadeados a partir do contato no século XVII. Tais atuações coloniais na região, em sua grande parte, foram impulsionadas pela exploração dos recursos naturais e mão de obra indígena (Oliveira Filho, 1988; López Garcés, 2003). Por meio delas, os Ticuna foram deslocados, paulatina e forçosamente, das terras firmes para as ribeiras do Solimões (Porro, 1992; Goulard \& Barry, 1998).

São abundantes as narrativas (tchiga) contadas pelos interlocutores tratando de suas próprias versões dos processos de constituição dessas territorialidades, hoje dispostas subnominadas entre Terras Indígenas e aldeias, nas cidades e nos espaços rurais adjacentes. Antes do estabelecimento dessas diversas linhas de fronteiras com as quais convivem ou classificam territórios que habitam, ou almejam fazê-lo, eles narram outro arcabouço de versões. Nelas abordam as diversas socialidades que deram formas e conteúdos ao conceito indígena de náane, glosado ora como território, território ancestral, ora como lugares onde habitam, moram, vivem os ticuna. Como uma entidade social e política (de la Cadena, 2010, 2015) no universo ontológico Magüta, náane, mais do que espaços habitados por diferentes categorias de sujeitos e territórios, corresponde a um agente, um estar/ser no mundo; ouvi ainda nesse mesmo sentido ser náane a nossa terra; ela tem sua história e jeitos de ser e cabe muita gente, indio ou branco ${ }^{4}$.

Da ideia mais geral de náane, para fins das discussões doravante propostas, nos interessa reter a presença de marcadores de diferenças ticuna que a constituem, atualizando-se também na gramática da nacionalidade e da conjugalidade, mobilizando as suas formulações de etnicidade e limites sociopolíticos próprios. Isso se observa a exemplo de quando adotam justapostos às insígnias e tchigas tradicionais

4 Santos Angarita (2013: 10 e passim) informa o conceito composto pelo morfema na- que designa "ser", indicando a $3^{\text {a }}$ pessoa singular; uma ideia de agente; $a$ - refere-se à raiz do verbo possuir, funcionando também como partícula indicativa de afinidade quando associada aos vocativos e termos de referência como a-wa-ne, por exemplo; -ne designa "imagem, figura, desenho, uma entidade"; “-ne refere-se ainda a corpo, a substância, a formas de vivência”. O que nos leva a tradução conjunta, em 2018: na - (ser) - a (possuir) - ne - materialidade agentivas; ser/estar no mundo. 
- além de nomes não indígenas - indicativos geopolíticos, reconhecendo-se, assim, enquanto ticuna brasileiro, ticuna colombiano ou ticuna peruano $0^{5}$; ou englobam e ressignificam juntos outros marcadores identitários-territoriais, ticuna de Tabatinga, de São Paulo de Olivença, de Tefé ou de Manaus; do Alto ou do Médio rio Solimões.

Inserida nesse conjunto de narrativas orais sobre produção de historicidades e marcadores de diferenças ticuna foi que encontrei subsídios junto com os interlocutores para o entendimento de suas categorias de alteridade, notadamente aquelas concebidas como awane $e^{6}$, os seus Outros, e as dinâmicas que elas desenham sobre os gradientes de relações matrimoniais, foco à época da pesquisa. Similar ao conceito relacional de nảane, que expressa um universo indígena aberto à multiplicidade e diferença, awane comunica uma forma particular de sua presença na construção do matrimônio de Constância e da consanguinização da alteridade potencial.

Awane é aplicada, para além do campo matrimonial, aos inimigos e àqueles agentes provindos do exterior, humanos ou não humanos; indígenas ou não. Dialogando com esses referentes, os interlocutores decompunham o sentido de um awane inserido numa miríade de figuras de afinidades potenciais, alocando nelas as chamadas gentes de fora. Tal categoria era usada para definir a condição de Juan, um não indígena e peruano, antes do processo de aliança matrimonial com Constância ganhar vida.

Numa exegese breve realizada por seu Firmino, de 78 anos, pai de Constância, awane e gentes de fora aparecem dotados de ambiguidades na cosmopolítica Ticuna, e sua procedência é situada em tempos primordiais, quando Yoi, um dos germanos míticos, criou as molduras que organizam a estrutura de troca matrimonial e ao estabelecer as regras das nações instaurou o tempo de surgimento do povo Magüta (povo pescado do rio). Ypi, irmão gêmeo de Yoi, foi responsável pelos inúmeros infortúnios que desencadearam eventos críticos de rupturas anteriores entre eles, culminando, numa temporalidade espiral, noutro período de refazer a náane. Dotado de atributos negativos, a Ypi é atribuída a criação das categorias de alteridade não ticuna. Nessa trama, durante um dos episódios de refazer a na' ane, aqueles pescados por Yoi tornaram-se Ticuna, recebendo clãs/naçôes e nomes particulares, enquanto os capturados por Ypi, sem tais insígnias, tornaram-se seus Outros; os awane, os brancos e sua variedade de possibilidades (missionários, gringos, peruanos, antropólogas), bem como os demais povos indígenas.

Percebe-se nessa digressão a trama classificatória expressando a condição de inimizade a priori concebida aos homens de fora, especificamente de origem peruana, conjunturalmente definida nas tchigas ticuna relacionadas também à historiografia regional. Nesse quadro referencial, essas figuras masculinas exteriores, materializadas na presença de Juan na aldeia, memoram interações que os situam em pontos de vista homólogos àquelas de afinidades potenciais, em duas temporalidades e escalas de distinção principais.

\footnotetext{
5 Sobre tema e a discussão do uso das prerrogativas de nacionalidade na tríplice fronteira interseccionado ao acesso de indígenas peruanos às políticas indigenistas brasileiras, ver também Medeiros (2010).

6 Awane é o termo genérico apresentado por muitos colaboradores ticuna para expressar aqueles que não são como eles, Magüta. $\mathrm{O}$ traduzem como inimigos, aqueles a quem temem. Na sequência da nota 4, a decomposição de awane nos permite entendê-la como entidade/imagem de fora, do exterior onde a partícula -wa é indicativa de lugar. Cf. Goulard (2009), Goulard e Barry (1998) e Montes Rodríguez (2004).
} 
No passado, esses homens não indígenas e peruanos estiveram associados com a gente de Ypi, caracterizada como o povo das mercadorias, das letras, do ouro e da ganância; que os roubavam, e por isso, tornaram-se gente de quem se desconfia. O mito de origem dos Magüta conhecido em campo localiza o Povo de Ypi geopoliticamente onde está, atualmente, o território peruano, na margem oposta daquela em que Yoi habita com os ancestrais, no Eware, à jusante do rio Solimões.

Agregado a essas relações nos tempos e espaços pretéritos, as imagens desprestigiadas associadas aos peruanos manifestam-se nos discursos Ticuna sobre os agentes coloniais, com especial ênfase naqueles atuantes no período da economia da borracha, no início do século XX, momento em que alguns dos parentes anciões de Constância relatavam ser tempos de suas andanças pelos beiradões, nas fazendas de seringa (Hevea brasiliensis) e sorva (Sorbus domestica). Durante esse período econômico, eles contam que esses estrangeiros atuavam como capatazes dos patróes que usavam de força para escravizar os indígenas e ganhar dinheiro na seringa, nas mercadorias. Esses homens de fora se interessavam por mulheres Ticuna só para se misturar e roubar terra, afirmavam os parentes de Constância.

Segundo Firmino, a memória dessas interações deletérias num tempo mais recente atualiza esses inimigos antigos, e masculinos, noutros avatares de poder ligados ainda à catequização católica e a evangelização, seja a partir dos anos de 1950, como os missionários norte-americanos vinculados à Igreja Batista, seja por outros ligados ao movimento messiânico da Cruzada (a este respeito, ver: Macedo, 1996). Ambas as interações, de modo similar, operaram ações civilizatórias por meio das quais se ouvia que ajudaram no esquecimento e a ter vergonh a do idioma, da comida de ticuna. Outras vezes, essas figuras estrangeiras peruanas eram mencionadas como perigosas, pelo envolvimento no tráfico de drogas, ou nas dinâmicas de comercialização de mercadorias pelos regatôes ${ }^{7}$ através de suas mobilidades pelo rio, ou ainda, relacionada aos comerciantes donos dos mercadinhos locais situados às margens das aldeias ou na cidade, onde recria-se e mantêm por ali novas dinâmicas e circuitos de aviamentos e dívidas.

Portanto, a ideia de awane, numa pluralidade de ocorrências, aparece entre os interlocutores como um conjunto comum de gramáticas relacionais estabelecidas na chave dos afetos de repulsas e violências características. Com efeito, a categoria comunica níveis de incorporação desses sujeitos nas transformações diversas ocorridas em seus modos de vida como Magüta. Neste marco relacional, em comparação com outros povos ameríndios, a diferença e alteridade são aos Ticuna também princípios constituintes, dentro dos quais awane pode ser empregado como termo que denota uma "verdadeira alteridade" (Lagrou, 2007:159).

Isso exposto, retomamos o problema etnográfico das lógicas de predação feminina exercida por Constância. Casar-se com gente de fora e peruana, nesse contexto particular, indica a dupla ambiguidade constitutiva do seu pretendente a cônjuge e desencadeia a necessidade de amansá-lo para familiarizar e controlar a diferença. Afinal, ser um homem de fora peruano denota uma ordem de exogamia sem valor positivo agregado dentro de suas lógicas de alianças matrimoniais e políticas antes descritas. Isso decorre, por um lado, porque estes homens não transmitem as insígnias identitárias (clã) num universo patrilinear, por serem não indígenas, ou porque ocupam incorporadas aos seus jeitos de ser

7 Pequeno comerciante fluvial, cuja embarcação circula entre nos rios e igarapés. 
posições deletérias, remetendo às situações adversas passadas, das quais os interlocutores buscam ter controle e autonomia.

\section{Gentes do outro lado do rio, inimigos de situação}

A proposição que nomeia essa seção resume outra chave importante do problema cosmopolítico enredando sentidos à produção da pessoa, do corpo e do parentesco em jogo no caso de Constância: conviver e habitar no outro lado do rio. Nesses meandros, na posição inicial de duplo estrangeiro, de nacionalidade e de jeitos, Juan era conhecido na aldeia na posição de inimigos de situação. A expressão descritiva e relacional era utilizada sempre em português e o associava intimamente à condição mutável de inimigo aos conjuntos de ambiguidades antes referidas por Firmino, indicando aspectos a serem controlados nas ações de modulações da pessoa e do parentesco.

Na continuidade da mesma descrição anterior de Firmino sobre categorias de afinidade, intrigava-me um detalhe comparativo, alusivo à decomposição da alteridade estrangeira. Ao qualificar como equivocado o casamento de sua filha pela condição do respectivo cônjuge como um tipo particular de awane, gente de fora, ele comparava estes laços conjugais ao seu próprio, efetivado com Lora, sua esposa e mãe de Constância. Lora também já foi gente do outro lado do rio, ouvi inúmeras vezes. Tal união conjugal, entretanto, diferentemente daquela indesejável inicialmente para Constância, era apresentada como certa, bem-feita, para Lora, outra gente de fora. A respeito da distinção, Firmino advertia-nos do nexo plural da ontologia nativa, mostrando a multiplicidade de mundos e sujeitos nela coexistentes: sou casado com uma parente, ela é ticuna de nascimento no Peru. Minha filha não. Seu esposo é homem de fora, um não ticuna verdadeiro, por isso não era bem-aceito, no jeito dos antigos.

Refletíamos ainda sobre o avesso dessa mesma situação: e se fosse ele o parente peruano e, sua esposa, a parenta ticuna brasileira? Nesse caso, ele mencionava, não se tratar exclusivamente de um problema do gênero do estrangeiro/alteridade, mas de parentesco, de similaridades ontológicas possíveis: não é porque são homens ou mulheres, éporque são gentes não indigenas, não ticuna. Sendo Ticuna, como sua esposa, é tudo parente, só que de jeitos diferentes. Portanto, trata-se de uma diferença englobante, um afim virtual, indo ao encontro do que Viveiros de Castro $(1995,2002 b)$ sugere a respeito de não haver consubstancialização sem alteridade.

Ouvindo isso, eu passava a fazer conexões sobre como nessas configurações as categorias sociocêntricas ticuna mobilizam as formas performáticas de parentesco entre os binômios reguláveis, afinidade e consanguinidade, e os valores e critérios gerativos dos gradientes de relação. Suspeito que nessa breve comparação evocada por Firmino estaria uma versão ticuna do modelo analítico que articula a hierarquia entre afinidade e consanguinidade como marcadores canônicos da alteridade e da identidade na Amazônia indígena. Nele vemos formulado o corolário, descrito por Viveiros de Castro (2002a), indicando que no nível do grupo local, a consanguinidade em termos comportamentais, ideológicos e terminológicos, prevalece sobre a afinidade, enquanto no nível supralocal esta hierarquia é invertida, e, no plano global, é a afinidade mesma que se impõe pela relação com o exterior. Este modelo distingue três manifestações básicas das relações de: afinidade efetiva/atual (cunhados, genros, 
sogros); afinidade virtual (primos cruzados); afinidade potencial/sociopolítica (cognatos distantes e não cognatos, peruanos).

A presença de Juan na aldeia faz aparecer estatutos que orbitam entre eixos contínuos e oscilantes de inimizade e aliança. $\mathrm{O}$ atributo da confiança antiga - ou sua falta - reaparece, então, como vetor mediador entre um afim potencial e virtual. Nesse horizonte, entende-se que a ideia da alteridade impressa em Juan é compreendida na assimilação, ou não, do inimigo potencial antes mesmo de pensá-lo como cônjuge e aliado. Seguindo as narrativas anteriores, Juan não poderia sê-lo, idealmente, porque está política e ontologicamente distante, residindo nesse nexo o objeto da relação de predação familiarizante empreendido por Constância.

Sua experiência evoca ainda outro corolário etnológico importante presente nesse processo de amansar o outro feminino, a presença dos Outros encobertos em diferentes aspectos da produção de pessoas e parentes. O que vemos ocorrer é que a despeito de perigosa, a alteridade faz-se necessária, condensando tanto a necessidade social de afins (Lévi-Strauss, 1993[1991]), quanto a necessidade política de inimigos (Albert, 1985; Overing, 1986; Fausto, 2001; Lagrou, 2007; Goulard, 2009).

Nessa lógica relacional, a diferença, já dizia Lévi-Strauss (2011[1947]; 1993[1991]), é o fundo contra o qual a semelhança é fabricada. Na perspectiva ticuna, retomando a diferença no componente da identidade étnica de Lora e Juan, vimos ser acionados gradientes de distinção basilares na captura e domesticação do outro. Aqueles de origem do outro lado do rio são parentes de longe: de pensamento e de aldeia, com a giria [língua indígena] no sotaque do Peru. Lora, diferentemente do que assumem seus parentes ticuna brasileiros como princípios de interação com Juan, veem-se todos a si mesmos inseridos no mesmo grupo humano, os Magüta, gente verdadeira pescada por Yoi. Juan ocupa outra perspectiva.

Mais do que isso, a explicação de Firmino e dos demais interlocutores demonstra que a fabricação do parentesco é um modo de desconstruir a afinidade potencial, quando afirma que aqueles parentes ticuna situados, contemporaneamente, no lado peruano de seus territórios, do outro lado do rio, tornam-se, pelo convívio, tudo meio parecido com esses inimigos. Nesse sentido, há que tomar cuidado. Dessa maneira, Lora e qualquer outro/a Ticuna de origem no outro lado do rio não são vetados à aliança matrimonial, mas é preciso, desde o ponto de vista desses sujeitos, inseri-los na gramática da convivialidade dita como ngu'ú. Um processo de incorporação cotidiana de regimes de conhecimentos e jeitos de estar no mundo; de fazer e ser parentes na náane.

Constância costumava glosar esse jeito de ser ticuna ou fazer de Juan um ticunado, uma espécie de princípio de relação local também nominado de marcar; algo no sentido de produzir/criar na pessoa certos jeitos (atributos sociais, étnico-culturais, morais, saberes e conhecimentos). Um exercício cotidiano de modulações e controles de assemelhamento ticuna, mantendo-se padrões de diferenciações, porque lembravam-se constantemente que muita proximidade gera womãtchi. Nessa arte perigosa e sensível de amansar pontos de vista de inimigos situacionais ou não, observa-se o exercício de borrar, no caso daqueles de origem peruana, eventuais vestígios depreciativos provenientes da proximidade simbólica, espacial e ontológica, com a gente do povo de Ypi e suas reconfigurações possíveis.

Situados acerca do lugar político e semântico dado para a categoria relacional awane, ora como categoria de afinidade virtual ora como potencial, cabe, então, conhecer de que modo Constância 
amansou a afinidade potencial e a alterou, pela predação familiarizante, em afinidade efetiva, matrimonial.

\section{Amansando o inimigo, construindo um afim matrimonial}

Juan estava aproximadamente com cinquenta e dois anos quando o conheci, em 2013. Em busca de trabalho, por volta de 1995, ele chegou sozinho e solteiro à aldeia onde mora Constância, depois de ter circulado por diferentes cidades peruanas e colombianas. Este trajeto iniciou-se quando, com dezessete anos de idade, ele deixou a casa de sua mãe, no interior rural da região de Loreto, na Amazônia peruana. Similar ao que diz ocorrer com jovens campesinos do lugar de origem, Juan saiu para tentar estudar e buscar emprego na cidade. Desde então, no tempo dessas andanças, muito pouco soube de sua família, convertendo-se no que caracterizavam os ticuna como nü̈in catama ma'ü ${ }^{8}$, homem sozinho no mundo; condição estranha ao modo de vida daqueles ticuna na aldeia. Causa inicial de desconfiança.

Como trabalhador autônomo, Juan acumulou experiências no manejo de madeira, tornando-se um exímio extrator, serralheiro e carpinteiro, inclusive no fabrico de canoas e casas. Foram tais aptidões técnicas que o tornaram inicial e temporariamente aceito na aldeia. Apesar da forte desconfiança, passados alguns meses na busca fracassada das lideranças locais, aceitaram conceder a ele o tempo de prova. Para ficar, ele trabalharia a baixo custo na fabricação de casas novas para a comunidade, sendo inserido nos mecanismos de funcionamento de trocas locais e suas formas de controle e poder sobre o Outro. Operuano, como o identificavam na aldeia, permaneceu durante quase dois anos morando numa choupana próxima da roça, distanciado do centro da aldeia. Ali ele ficou sob vigilância das autoridades, enquanto trabalhava, até que, paulatinamente, seu trabalho deixou de ser remunerado, passando a ser realizado em troca de abrigo e autorização para cultivo na aldeia. De obrigações, suas atividades tornaram-se elos no regime de trocas.

Juan, como estratégia de aproximação e troca, tratou de se alinhar aos outros estrangeiros peruanos que ali viviam, a exemplo de dois irmãos de Lora. Ainda que ele fosse consciente da distinção étnica e moral existentes entre eles, e respeitando a indiferença recebida, Juan, por necessidade de comunicação, buscou entre esses outros homens de fora alguma facilidade linguística que lhe desse apoio ao dialogar com o cacique, que demonstrava pouca disposição para compreender seu castelhano ou português. Nessa tensionada e controlada interação, não tardou muito para que ele conhecesse Constância, àquela altura com seus quase trinta anos. Ela recebia os peixes que Juan pescava em troca pelo apoio recebido de seus tios maternos, ou em troca de alimentos e outros itens. A motivação de Constância por agradar à potência perigosa e instalar-se no circuito de trocas com o afim potencial instaurado pelas lideranças ocorre quando finalizado o tempo de prova do peruano.

Na ocasião da chegada de Juan à aldeia, Constância encontrava-se em uma situação difícil, estava marü manay $a^{9}$, associada à sua solteirice prolongada. Por isso, ela estava alocada em uma situação desfavorável, de uma mulber velha com panema de marido. Solteira, habitando na casa dos pais e sem

8 Do ponto de vista Ticuna, alguém que vive solitário é uma pessoa incompleta.

9 Expressão que descreve mulher que já passa do tempo de casar-se; fica velha sem marido. 
pretendentes locais para cônjuge, tampouco com desejo de retirar-se da aldeia em busca de um, ela sentia vergonha (änï) perante outras mulheres.

Para driblar tal condição, ela analisava que, de modo distinto ao de algumas de suas parentas mais próximas, cujos matrimônios foram arranjados pelos pais ainda quando jovens, foi ela quem buscou o inimigo como esposo. Para escapar da má sorte matrimonial, ela relata que, quando soube da presença de Juan, surpreendeu-se com a beleza do estrangeiro, diferente dos homens ticuna, mas, também de pele morena e cabelos negros, cara de gente do mato.

Nesses critérios lhe faltavam, porém, aqueles quesitos prescritos nas estruturas de trocas simbólicas e princípios exogâmicos convencionais e, mais do que isso, nas preferências políticas das lideranças e seus parentes sobre a condição de dupla ambiguidade: não ticuna e peruano, visto anteriormente. Chamo atenção aqui às equações plurais operacionalizadas no desenrolar do tratamento a alteridade estrangeira e seus efeitos sobre as relações matrimoniais e de afinidade coextensivas à fabricação da pessoa e do corpo, desde o domínio das socialidades femininas.

Enquanto as lideranças - majoritariamente figuras masculinas - exerciam o controle da alteridade por meio da afinização predatória, mediada pelo serviço prestado por Juan, Constância, por sua vez, tratava de capturá-lo e, criativamente, familiarizá-lo. Nessa lógica, poder-se-ia sugerir que Constância, ao fazê-lo, estabelecia terrenos para futuras alianças necessárias ao processo de constituição de sua conjugalidade desejada. Com isso, num mesmo movimento, ela propõe alterar duas relações por meio do fluxo de incorporação da alteridade e estabelecimento de limites à diferença do estrangeiro. Ela altera duas posições relacionais, ao menos.

Ela desloca-se de estar com panema de marido para mulher nguée ante’e rü ããcüěe, casada e com filhos. Ele, pelo esmero e trabalho prestado na aldeia sem causar transtornos, criou possibilidades para que Constância justificasse, perante as lideranças, ao seu pai, e aos seus familiares, as gramáticas constituintes de seus afetos e de suas próprias vontades subjacentes à escolha por amansar (ina) aquele homem de fora. Como sugerido na introdução, chama-se atenção para a operação de amansar o inimigo de situação explicada como inanaü̈̈̈ ${ }^{10}$, algo criado ou produzido por ela para contribuir também com o coletivo. Para viabilizar isso, era preciso marcar Juan para assumir a posição de yatu amacü rü âaüücü, homem casado e com filhos.

Nota-se nesse processo que Juan buscava adquirir capacidades para tornar-se um afim virtual, estabelecendo-se na aldeia. Converteu-se à religião local como solicitam as lideranças, passou a aprender um pouco do idioma indígena, produziu uma roça comunitária com ajuda de outros homens, além dos serviços com madeira prestados à aldeia durante o tempo de prova.

Para alterá-lo em um aparentado, um ticunado, Constância acionava as forças do homem para virar bom marido. Ela lhe cozinhava comida de indio, com suas macaxeiras e batatas como base, ingredientes basilares nas economias de troca conjugais, assim como nos processos de produção de estado de ânimo (porá). Ela falava contar com a ajuda de alimentos específicos, os nawemugü, considerados forti-

10 A expressão traduz a ideia associada ao ato e capacidades de domesticar, criar. Ela é usualmente empregada para falar de cultivares específicos (mandioca, cará, frutas) que estão sob responsabilidade das mulheres. Inanaüü também define o ato de nomear os filhos ao nascer, realizados entre as mulheres, marcando a relação alterada (Strathern, 2001) na produção da pessoa, uma vez que o clã é patrilinear. 
ficados, dotados de capacidades agentivas produtoras do corpo-pensamento (mẩü) ticuna. Para marcar o jeito ticunado em Juan, ela e suas parentas ofereciam caldo de peixe com farinha e o pajuaru (bebida fermentada de mandioca oriunda da roça de Constância), este último, cabe lembrar, responsável por criar nos homens uma substância corporal masculina (namũ), associada nas traduções que conheci ao sêmen, através da qual se transmitem os clãs aos filhos.

Nesse processo de comensalidade, Constância exercia a consubstanciação que domesticaria o corpo-pensamento ( $m \tilde{a} \ddot{u})$ de gente de fora em um ticunado. Ambos estavam empenhados para que a mistura com gente de fora se tornasse produtiva, ainda antes do casamento efetivar-se, em 1999. Por vezes, Constância também se enfeitava e preparava comida à parte, condimentada, que não é muito apreciada ao gosto ticuna local. Fazia para que Juan não fugisse. Limpava as roupas dele, que apesar de ser uma ação remunerada no início, era um modo de mostrar-lhe suas habilidades de cuidado. Constância fazia questão também de mostrar-lhe a fartura de sua roça como modo de marcar/moldar o gosto dele por ela; tudo isso era um tipo de armadilha, jeito de caçar marido, ela dizia. No decorrer desses jogos de sedução, ela e Juan reciprocamente se afeiçoaram, mantendo esporádicos encontros.

Com intermédio dessas estratégias associadas com sexo, cuidado e comida como meio de domesticar e consubstancializar, ela comentava ter amansado o inimigo, trazendo-o aos poucos para a negociação do casamento. Além dessas técnicas de captura, ela incentivava-o para desempenhar as demandas e dava pistas do que agradaria as lideranças; reforçava com ele formas básicas de comunicação na língua indígena, aprendida depois de alguns anos. Ademais, Juan sabia pescar muito bem, especialmente alguns peixes de grande porte, habilidades que seus futuros cunhados não tinham e que Constância, orgulhosa, tratara de cooptar a seu favor.

Através dessa familiarização interessada, ela pontuava que mulheres não pescam, precisam de seus maridos, cunhados, filhos. Na falta deles, e para estabilizar suas redes de reciprocidade, ela amansou Juan e $f e z$ (atuou por mediação dele) como os homens que vão buscar peixe, caça para alimentar os seus parentes. Ela atuava, desse modo, não assumindo a perspectiva masculina, mas agenciando as capacidades potenciais de Juan, de modo a garantir bons peixes e fartura aos seus parentes e, com isso, assegurar espaços de troca e interação local para ele satisfazer os critérios matrimoniais desejáveis. Ela faz aparecer, nas arenas de domínios femininos cotidianos, também mecanismos de captura, predação e consumo da alteridade exterior e, desta maneira, inverte a perspectiva comum da domesticação da afinidade.

Numa frutífera analogia com o universo das agências masculinas, comumente atreladas nas leituras antropológicas ao provento de proteínas e o exercício de interação com o exterior perigoso, a postura da interlocutora permite observarmos dois movimentos de predação familiarizante em marcha, portanto. Enquanto as lideranças mantinham a alteridade distante, numa posição de afinização marcada por desconfiança, ignorando-a e dificultando sua circulação, permitindo-a ocupar, desse modo, o domínio secundário de socialidade entre os homens, Constância, a seu modo, buscava paulatinamente, criar elementos de familiarização a ponto de tornar o inimigo atrativa para a consubstancialização.

Nesse processo, parece que a consanguinização prevaleceu sobre a afinidade, uma vez que Juan deixou-se alterar de perspectiva, adquirindo condições agentivas que o tornassem um homem de confiança. Juan adotou pontos de vista de homens ticuna, assumindo formas de socialidade similares àque- 
las que realizam seus novos parentes. Ao casar-se com Constância, construiu para ela uma grande casa e levou-a para com ele morar. Logo tiveram o primeiro de seus quatro filhos. Ambos viviam com a renda provinda dos trabalhos com madeira e na roça e juntos adquiriram um freezer elétrico, cuja água fresca dava inveja nas parentas.

Outro movimento ocorre nesse processo de predação familiarizante proposto por Constância. Juan é um não ticuna, e, portanto, sem insígnia clânica herdada de seus parentes homens ascendentes, que pudesse transmitir aos filhos. De origem estrangeira, e incorporado nas relaçóes pelo casamento com Constância, a ele foi atribuído o clã de woca (boi/vaca). Lora, quem o nominou, dizia que tal clã funciona como emblema identitário, evidenciando o exterior contido nos domínios de socialidades locais. Ele insere um elemento (animal) do universo ontológico dos brancos no âmbito do sistema classificatório ticuna como índice ao qualitativo gente/parente ticunado; aquele que virou um parente. Esse clã contrapõe-se criativamente ao grupo daqueles de clã de gente legítima, não misturada, indicando pessoas cujo pai é ticuna.

A estratégia adotada para amansar Juan ao nominá-lo traduz o clã de boi como mais uma nuance da fórmula relacional ticuna da "filosofia da boa distância" (Overing, 1986), assumindo o lugar de operador que indica a estabilização das diferenças e modos possíveis de administração da alteridade. A presença do clã woca, assim como dizem ser o de ota (frango), mostra que assim como a náane e as categorias de outros (awane) são moldáveis. Às lógicas de classificação da identidade ticuna englobam-se as distinções simbólicas do outro e, com isso, se produz jeitos de ser parente diversificados. A lógica do parentesco indígena aqui produzida por Constância compõe, por outros meios menos bélicos ou rituais, o movimento de trazer o terceiro incluído; ela o faz de modo diversificado e em paralelo àquelas ações realizadas pelos parentes em domínios masculinos de socialidades.

Por fim, cabe revisitar outra escala dessa socialidade, na qual é possível identificar os efeitos das ações de familiarização do inimigo feitas por Constância. Em certa ocasião, depois de sua mãe relatar sobre atrocidades da vivência ainda criança no seringal, no Peru, Constância afirmara que havia laçado aquele homem de fora, aludindo suas técnicas de predação àquelas empregadas pelos antigos capatazes peruanos às mulheres indígenas, caçadas e laçadas.

Ao enunciar tal preposição, ela faz possível notar também que, através do processo de amansar marido e pelo casamento, inverte-se a posição do sedutor e predador antes mencionados por Firmino e por ela própria sobre a relação predatória realizada pelos homens de fora, do outro lado do rio. Nesse sentido, Constância atua com métodos de controle similares ao modo como atuavam aqueles homens peruanos no tempo da seringa, desprezados tanto pelas mulheres quanto pelos homens da aldeia. Se a memória ticuna em relação aos homens peruanos lembra as capacidades deletérias de atração das mulheres Magüta e de exploração de seus territórios e recursos, a predação familiarizante levada a cabo por Constância converte-se, pois, em um ato reverso a favor não apenas de sua negociação marital e de uma cosmopolítica, possibilitando canibalizar, não sozinha, os atributos do afim potencial, na forma de recebimento de madeiras, casas e canoas novas, afetos e prestígios, num novo parente, marido, pai e cunhado. 


\section{Considerações inacabadas}

Ao longo do texto buscou-se mostrar como, nas relações de parentesco e política ticuna, circulam valores e perspectivas das experiências sobre os mundos vividos e práticas indígenas de fabricar pessoas e parentes. Amansar marido no jeito da mulher ticuna, como diz Constância, mostrou diversos afetos e histórias que constituem e coexistem nos pontos de vista conectados nessas interações concernentes ao predar o inimigo situacional, alterando sua posição de afim potencial a um afim virtual. Um ticunado, afim reconhecível a ponto de estar dotado da capacidade matrimonial. Assim, o modo de familiarizar o inimigo foi apresentado com mecanismo de apropriação de potencialidades estrangeiras e perigosas para tranformá-las em aspectos significativos quanto ao modo de vida na aldeia e às regras de convivência e da aliança matrimonial.

Aliado à proposta da centralidade da "diferença necessária" (Overing, 1983/1984), o exercício proposto foi conjugar a ideia mais geral do "esquema da predação familiarizante" (Viveiros de Castro, 2002b; Fausto, 2001; Santos, 2019), porém, deslocando o objeto da ação do domínio de socialidades masculinas na guerra, no xamanismo e no ritual, para o cotidiano das relações entre homens e mulheres na elaboração de sentidos ao casamento e à fabricação de parentes. Disso, ela e seus parentes criaram condições para apropriar-se das capacidades do inimigo, amansando do seu jeito, para torná-lo um terceiro incluído (Viveiros de Castro, 2002a, 2002b). A modulação do marido amansado pelo casamento, em especial, abarca o espaço criativo das "reclassificações" (Lévi-Strauss, 1993 [1991]) dos gradientes de identificação e diferenciação. Como elucidam as experiências aqui apresentadas, a pessoa estrangeira ao alterar-se em ticunado o faz mediante o reconhecimento do seu parentesco, redesenhando o estatuto definidor da condição de aliança em jogo, inclusive sua onomástica.

A novidade nesse contexto é de que isso somente ocorre no paralelismo das socialidades descritas entre homens peruanos e mulheres Ticuna, ações geradas nos domínios internos e generizados, alternadas de cada conjunto de capacidades agentivas envolvidas (Strathern, 1992). Foi na dinâmica do dia a dia que observamos que o domínio do cotidiano e da interioridade se torna fundamentais nesse processo de familiarização de gentes de fora, nem fora nem à margem ou periferia de outros processos.

Mostrou-se esse evento particular de predação feminina ainda como um duplo processo de transformações de posições, tanto de parentesco quanto política-moral que nos permite refletir sobre alguns componentes resultantes desse exercício feminino de predação familiarizante. Ao mesmo tempo em que Constância constrói para si um o espaço de relação para obter esposo reconhecido, na forma ticunado, tratando de alterar sua própria posição relacional e condição política-moral na aldeia de mulher com panema de marido em alguém casada, com filhos e redes de trocas consolidadas, ela passa a ser, junto com ele, capaz de fornecer afins e alimentar redes de reciprocidades. Se ela se encontrava, antes da captura de Juan como afim matrimonial, com jeito de mulher malfeito, ao neutralizar uma alteridade específica para ser incorporada no casamento que negociou, ela tornou-se uma mulher que dá inveja nas parentas, e ele, um parente ticunado.

Ao casar-se capturando e amansando marido, a interlocutora nos permite ainda seguir pensando sobre o lugar e potencial das agências femininas de algumas mulheres ticuna em reorganizarem a trans- 
missão patrilinear para, com isso, gerarem prospectivamente espaços de expansão para as boas regras de convivências, quando seus filhos casaram-se com mulheres ticuna. Assim, o clã de gente de fora (woca) herdado pelos filhos do casal mostra que consanguinidade engloba no plano do local a afinidade. Ao ser reconhecido como transmissor ticunado, um pai/parente de clã woca, a diferença contida em Juan torna-se controlada e domesticada. E, por tal, ela passa socialmente a ser reconhecida e valorizada, estimulando os deslocamentos de posições descritos. Observamos a transformação de uma aliança inicialmente equivocada desejada por Constância e Juan, carregada de afetos políticos, econômicos e éticos, em um vínculo-aliança, um casamento, bem avaliado.

Constância define seu processo de aliança como um ato de caçar marido, no âmbito do qual tal ação presta-se como vetor dessa dupla transformação, da diferença na sua condição feminina, e da alteridade num bom esposo, expressa no processo ticunização de Juan. Efetivadas mediante o que denominam estes interlocutores tempos de prova e o casamento, essas ações foram analisadas aqui como dois momentos de "predação familiarizante" (Fausto, 2001), com destaque ao segundo.

Patricia C. Rosa é Doutora em Antropologia Social pela Universidade de Campinas (UNICAMP) e Pesquisadora Titular no Instituto de Desenvolvimento Sustentável Mamirauá (IDSM), atuando nos grupos de pesquisa Territorialidades e Governança Socioambiental e Arqueologia e Gestão do Patrimônio Cultural da Amazônia.

Esta pesquisa foi financiada pelo Conselho Nacional de Desenvolvimento Cientifico e Tecnológico - CNPq, entre 2011 e 2014.

\section{REFERÊNCIAS}

Albert, B. (1985). Temps Du Sang, Temps des Cendres. Représentation de la maladie, système rituel et espace politique chez les Yanomani du sud-est (Tese de Doutorado). Laboratoire d'ethnologie et de sociologie comparative. Université de Paris X, Paris.

Archambault, J. S. (2016). Taking love seriously in human-plant relations in Mozambique: toward an anthropology of affective encounters. Cultural Anthropology, 31(2), 244-271. https://doi. org/10.14506/ca31.2.05

Belaunde, L. E. (2001). Viviendo Bien: Género y Fertilidad entre los Airo-Pai de la Amazonia Peruana. Lima: CAAAP / BCRP.

de la Cadena, M. (2010). Indigenous Cosmopolitics in the Andes: Conceptual Reflections Beyond 'Politics'. Cultural Anthropology, 25(2), 334-70. https://doi.org/10.1111/j.1548-1360.2010.01061.x 
de la Cadena, M. (2015). Earth beings: ecologies of practice across Andean worlds. Durham: Duke University Press.

Descola, P. (2001). The gender of gender: local models and global paradigms in the comparison of Amazonia and Melanesia. In T. A. Gregor, \& D. Tuzin (eds.). Gender in Amazonia and Melanesia. An exploration of the comparative method (pp. 91-114). Berkeley: University of California.

Fausto, C. (2001). Inimigos fiéis: história, guerra e xamanismo na Amazônia. São Paulo: EDUSP.

Goulard, J-P. (1998). Les genres du Corps: conceptions de la personne chez les Ticuna de haute Amazonia. (Tese de Doutorado) Departamento de Antropologia e Etnologia, École de Hautes Etudes em Sciences Sociales, Paris.

Goulard, J-P. (2009). Entre Mortales e Inmortales. El ser Ticuna de la Amazonía. Centro Amazónico de Antropología y Aplicación Práctica (CAAAP). Lima: Instituto Francés de Estudios Andinos.

Goulard, J-P., \& Barry, L. S. (1998). Un mode de composition de l'alliance: le mariage oblique'ticuna. Journal de la Société des Américanistes, 84(1)1, 219-236.

Haraway, D. (1991[1988]). Situated Knowledges: The Science Question in Feminism and the Privilege of Partial Perspective. In Symians, Cyborgs and Women: the Reinvention of Nature (pp 183202). New York: Routledge.

Hugh-Jones, C. (1979). From the milk river: spatial and temporal processes in Northwest Amazonia. Cambridge: Cambridge University Press.

Lagrou, E. (2007). A fluidez da forma: arte, alteridade e agência em uma sociedade amazônica (Kaxinawa, Acre). Rio de Janeiro: Topbooks.

Lasmar, C. (1999). Mulheres Indígenas: Representações. Revista Estudos Feministas, 7(1), 143-153. https://periodicos.ufsc.br/index.php/ref/article/view/11989

Lasmar, C. (2005). De volta ao Lago do Leite: gênero e transformação no Alto Rio Negro. Rio de Janeiro: NUTI.

Lasmar, C. (2008). Irmã de índio, mulher de branco: perspectivas femininas no alto rio Negro. Mana, 14(2), 429-454. https://doi.org/10.1590/S0104-93132008000200006

Lea, V. (2001). Parentesco enquanto uma elaboração sócio-cultural da percepção do dimorfismo sexual humano. Encontro anual da ANPOCS, Seminário Temático Sexualidade, reprodução, filiação. Caxambu.

Lea, V. (1999). Desnaturalizando gênero na sociedade Mebengokre. Revista Estudos Feministas, 7(1), 176-194. https://periodicos.ufsc.br/index.php/ref/article/view/11991 
Lévi-Strauss, C. (1993[1991]). História de Lince. São Paulo: Companhia das Letras.

Lévi-Strauss, C. (2011[1947]). As estruturas elementares do parentesco. São Paulo: Vozes.

Lima, T S. (2005). Um peixe olhou para mim. O povo Yudjá e a perspectiva. São Paulo: ISA/ Editora Unesp/ NuTI.

López Garcés. Cl. (2003). Etnicidad y nacionalidad em la frontera entre Brasil, Colombia y Peru. Los Ticunas frente los processos de nacionalidade. In C. I. García (ed.). Fronteiras, Territorios e Metaforas (pp. 147-160). Medellín: Instituto de Estudios Regionales, INER, Universidad de Antioquia.

Macedo, G M. (1996). A conversão cristã e a identidade Ticuna: a trajetória de Campo Alegre. In Os Ticuna hoje (pp. 175-194). Manaus: Manaus Editora/UFAM.

McCallum, C. (2001). Gender ande Sociality in Amazonia. How Real People are made. Oxford: Berg Publishers.

McCallum, C. (2002). Inimigos fiéis: história, guerra e xamanismo na Amazônia. Mana, 8(2): 195198. https://doi.org/10.1590/S0104-93132002000200008

Medeiros, A. K. M. (2013). Direitos indigenas entre fronteiras: cidadania, presença e mobilidade ticuna na tríplice fronteira do Brasil, Colômbia e Peru. (Dissertação de Mestrado.) Programa de Pós-Graduação em Direito Ambiental, Escola Superior em Ciências Sociais, Universidade do Estado de Manaus, Manaus.

Montes Rodríguez, M. E. (2004). Morfosintaxis de la lengua tikuna: Amazonia Colombiana. Bogotá: Ediciones Uniandes.

Nimuendaju, C. (1972[1952]). The Tukuna. UCPAAE, v. 45. Berkeley, Los Angeles: University of California Press.

Oliveira Filho, J. P. (1988). Nosso Governo: os Ticuna e o regime tutelar. São Paulo: Marco Zero.

Overing, J. (1983/84). Elementary Structures of Reciprocity: a comparative note on guianese, central brazilian andnorth-weat amazon socio-political thought. Antropológica, 59(62), 331-348.

Overing, J. (1986). Images os cannibalism, death and domination in a 'non-violent' society. Journal de la Société des Américanistes, 72, 133-156. https://doi.org/10.3406/jsa.1986.1001

Overing, J. (2002). Estruturas elementares da reciprocidade. Cadernos de Campo, 10(10), 117-138. https://doi.org/10.11606/issn.2316-9133.v10i10p117-138

Porro, A. (1992). As crônicas do rio Amazonas. Notas etno-históricas sobre as antigas populações indigenas da Amazônia. Petrópolis: Vozes. 
Rapapport, J. (2007). Más allá de la escritura: la epistemología de la etnografía en colaboración. Revista Colombiana de Antropología, 43, 197-229.

Rosa, P. C. (2013). Romance de primas com primas e o problema dos afetos: parentesco e micropolítica de relacionamentos entre interlocutores tikuna, sudoeste amazônico. Cadernos Pagu, 41, 77-85. http://dx.doi.org/10.1590/S0104-83332013000200008

Rosa, P. C. (2015). Das misturas de palavras e histórias: etnografia das micropoliticas de parentesco e os "muitos jeitos de ser Ticuna"(Tese de Doutorado). Departamento de Antropologia Social, Universidade Estadual de Campinas, Campinas.

Rosa, P. C. (2016). Do "sexo malfeito". Transformações morais e dispositivos de sexualidade indígena. Aceno, 3(5), 73-93. https://periodicoscientificos.ufmt.br/ojs/index.php/aceno/article/view/3830

Rosa, P. C. (2019). Sobre as diferentes formas de habitar as normas e ativar modulações no parentesco: um caso ticuna. Amazônica. Revista de Antropologia, 11(2), 711 - 738. http://dx.doi. org/10.18542/amazonica.v11i2.7497

Santos, J. O. (2019). Sobre mulheres brabas: ritual, gênero e perspectiva. Amazônica. Revista de Antropologia, 11(2), 607-635. http://dx.doi.org/10.18542/amazonica.v11i2.7643

Santos Angarita, A. (2010). Narración tikuna del origen del territorio y de los humanos. Mundo Amazónico, 1(1), 303-314. https://doi.org/10.5113/ma.1.10900

Santos Angarita, A. (2013). Percepción tikuna de Naane y Naüne: territorio y cuerpo (Tese de Mestrado). Programa de Pós-Graduação em Estudos Amazônicos, Universidad Nacional da Colômbia, Sede Leticia, Colômbia.

Strathern, M. (1992). Parts and wholes: refiguring relationships in a post-plural world. In: A. Kuper (ed.). Conceptualizing society (pp. 74-104.). Londres/Nova York: Routledge.

Strathern, M. (2001). Same-Sex and Cross-Sex Relations. Some Internal Comparisons. In D. F. Tuzin (ed.). Gender in Amazonia and Melanesia: an exploration of the comparative method (pp. 221-242). Berkeley: University of California.

Vilaça, A. (2006). Quem somos nós: os Wari' encontram os brancos. Rio de Janeiro: Editora da UFRJ.

Viveiros de Castro, E. (1995). Antropologia do parentesco: estudos ameríndios. Rio de Janeiro: Editora da UFRJ.

Viveiros de Castro, E. (1996). Images of nature and society in Amazonian ethnology. Annual Review of Anthropology, 25, 179-200. https://doi.org/10.1146/annurev.anthro.25.1.179 
Viveiros de Castro, E. (2002a). O problema da afinidade na Amazônia. In A inconstância da alma selvagem (pp. 87-180). São Paulo: Cosac \& Naify Edições.

Viveiros de Castro, E. (2002b). Atualização e contra-efetuação do virtual: o processo do parentesco. In: A inconstância da alma selvagem (pp. 401-455). São Paulo: Cosac \& Naify Edições.

Viveiros de Castro, E. (2004). Perspectival anthropology and the method of controlled equivocation. Tipiti, 2(1), 3-22. 


\title{
AMANSAR INIMIGOS: PRÁtiCAS DE PREDAÇÃo FEMININA E A CONSANGUINIZA- ÇÃO DA ALTERIDADE
}

Resumo: Para interlocutores Ticuna casar e constituir conjugalidade são formas particulares de expressar as relações entre pessoas e suas capacidades agentivas, fazendo aparecer domínios generizados de socialidades através dos quais observamos operar regimes complexos de saberes, estruturas de troca e de etiquetas políticas. Ao examinar o processo matrimonial de Constância, este texto lança luzes sobre modos ticuna de administrar relações de parentesco, especificamente aquelas mobilizadas pelas capacidades predatórias femininas relacionadas à domesticação de uma categoria de afinidade potencial interétnica, transformada em um genro verdadeiro. A partir dessa situação etnográfica apresenta-se uma formulação inicial sobre práticas femininas de consanguinização de pontos de vista outros, acompanhando, para isso, os sentidos contidos nas ações de amansar marido, alterando antigos inimigos em bons esposos.

Palavras-chave: mulheres ticuna; gênero; parentesco; aliança.

\section{TAMING ENEMIES: FEMALE PREDATION PRACTICES AND THE CONSANGUINI- ZATION OF OTHERNESS}

\begin{abstract}
For Ticuna's interlocutors, marrying and constituting conjugality are particular ways of expressing the relationships between people and their agentive capacities, making generalized domains of socialities appear through which we observe the operation of complex regimes of knowledge, exchange structures and political labels. In the examinination of Constância's matrimonial process, this text sheds light on Ticuna ways of managing kinship relationships, specifically those mobilized by female predatory capacities related to the domestication of a potential interethnic affinity category turned into a true son-in-law. From this ethnographic situation, an initial formulation of female practices of consanguinization from other points of view is presented, accompanying, for this, the meanings contained in the actions of taming a husband, changing old enemies in good spouses.
\end{abstract}

Keywords: Ticuna women; genre; kinship; alliance.

RECEBIDO : $25 / 01 / 2021$

ACEITO: $31 / 08 / 2021$ 